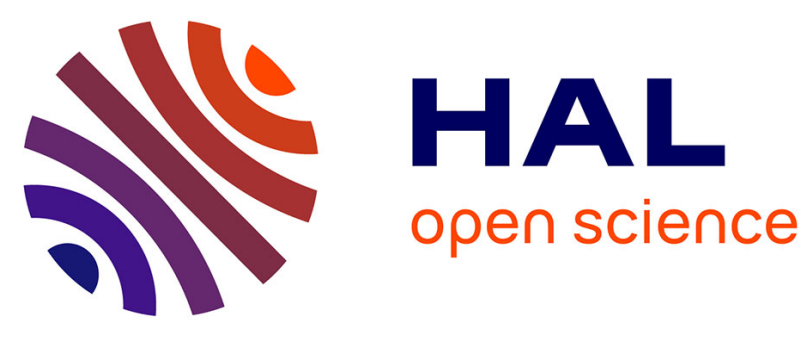

\title{
The Microstructure, Texture and Mechanical Properties of Friction Stir Welded Aluminum Alloy
}

Saliha Gachi, Mouloud Aissani, Thierry Baudin, Anne-Laure Helbert, Francois Brisset, Sébastien Gautrot, Marie-Helene Mathon, Djamel Bradai, Fouad Boubenider

\section{To cite this version:}

Saliha Gachi, Mouloud Aissani, Thierry Baudin, Anne-Laure Helbert, Francois Brisset, et al.. The Microstructure, Texture and Mechanical Properties of Friction Stir Welded Aluminum Alloy. Russian journal of non-ferrous metals, 2020, 61 (5), pp.523-533. 10.3103/S1067821220050041 . hal-03010660

\section{HAL Id: hal-03010660 https://hal.science/hal-03010660}

Submitted on 17 Nov 2020

HAL is a multi-disciplinary open access archive for the deposit and dissemination of scientific research documents, whether they are published or not. The documents may come from teaching and research institutions in France or abroad, or from public or private research centers.
L'archive ouverte pluridisciplinaire $\mathbf{H A L}$, est destinée au dépôt et à la diffusion de documents scientifiques de niveau recherche, publiés ou non, émanant des établissements d'enseignement et de recherche français ou étrangers, des laboratoires publics ou privés. 
Saliha Gachi ${ }^{\text {a }}$, Mouloud Aissani ${ }^{\mathrm{b}}$, Thierry Baudin ${ }^{\mathrm{c}}$, Anne.Laure Helbert $^{\mathrm{c}}$, François Brisset ${ }^{\mathrm{c}}$, Sébastien Gautrot $^{\mathrm{d}}$, Marie-Hélène Mathon ${ }^{\mathrm{d}}$, Djamel Bradai ${ }^{\mathrm{a}}$, Fouad Boubenider ${ }^{\mathrm{a}}$

${ }^{\text {a }}$ Faculty of Physics, University of Sciences and Technology Houari Boumediene, BP 32 El-Alia, 16111, Algiers, Algeria

${ }^{\mathrm{b}}$ Research Center in Industrial Technologies CRTI, P.O. Box 64, 16014 Cheraga, Algiers, Algeria

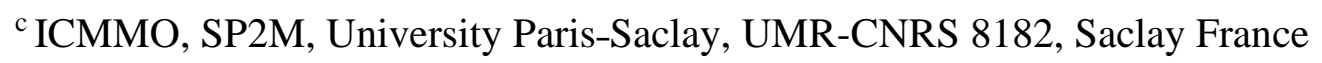

${ }^{\text {d }}$ Laboratory Léon Brillouin, CEA-CNRS, CEA/Saclay, France

Correspondence author e-mail: s_gachi@yahoo.fr

\title{
Microstructure, texture and mechanical properties of friction stir welded
}

\section{aluminum alloy}

\begin{abstract}
The microstructure and texture of 7075-T6 FSW weld with optimal parameters were investigated using optical microscopy, electron back scatter diffraction and neutron diffraction. The mechanical properties were also characterized through microhardness, nanoindentation and ultrasonic tests. The friction stir welding was performed at a nominal rotational speed of $1400 \mathrm{rpm}$ and a traverse speed of $60 \mathrm{~mm} / \mathrm{min}$.

The nugget zone contained fine, equiaxed and fully recrystallized grains. The texture of the base material mainly consisted of Cube and rotated Goss components. However in the nugget zone, the dominant texture components were $\mathrm{B}$ and $\overline{\mathrm{B}}$ among common shear orientations.

Elastic modulus was measured by ultrasonic and nanoindentation methods. The ultrasonic one has the main advantageous to be nondestructive, easy, inexpensive and fast. A little increase of Young modulus is observed in nugget zone compared to base metal.
\end{abstract}

Keywords: Aluminum alloy, FSW, Microstructure, Texture, Microhardness, Young modulus. 


\section{Introduction}

One of the main materials used for aeronautical applications is the heat treatable 7075 aluminum alloy. It fulfills the main requirements of weight, availability, formability, cost, reliability and maintainability. Due to its excellent strength/weight ratio, this alloy is widely used for the fuselage, the wings and the supporting structure. Unfortunately, fusion welding of this alloy is difficult by conventional techniques due to its copper content which leads to a solidification and liquation cracking in the heat affected zone with a great reduction in mechanical properties within the joint $[1,2]$.

Friction stir welding (FSW) has been proved as a powerful joining method and has matured over the last two decades for various metals and alloys. The main advantages of this processing are that it produces materials free of distortion, cracks, porosity, oxidation, and other defects that result after conventional fusion welding to improve the mechanical properties of the weld [1,2].

In this process, a cylindrical tool composed essentially of a shoulder and profiled pin is rotated and inserted into the adjacent edges of the clamped work pieces to be welded. Frictional heat between the wear resistant tool and the workpieces causes the softening of material without reaching melting phase allowing the tool to move along the joint line. As a result, a weld joint is produced in solid state. Near the center of the weld, is located the nugget zone (NZ), also called dynamically recrystallized zone. This region consists of fine equiaxed grains that are formed by dynamic recrystallization due to the severe plastic deformation and high temperature. An extra zone is created between the nugget zone and the base metal (BM), namely the thermo-mechanically affected zone (TMAZ). The reason for the formation of this area is that the workpiece is subject to both temperature and deformation during the welding process. This is the different point from the other general welding methods. TMAZ is characterized by a highly deformed structure. It is followed by the heat affected zone (HAZ) which experiences a thermal cycle but did undergo any plastic deformation [3].

The FSW process is not symmetric with respect to the weld line. The advancing side (AS) is the zone where the rotational and welding speed have the same direction whereas in the retreating side (RS), the two velocities have opposite directions.

Numerous published reports [4-13] indicate that there is strong microstructural and textural evolution in similar and dissimilar heat treatable aluminum joints that are characterized by the thermal and deformation histories. These authors evidenced the occurrence of a recrystallization concomitant with the texture change and both contributed to the grain refinement of a stirred zone down to the sub-micrometer level. 
FSW of 7xxx-series aluminum alloy was the subject of many studies including mechanical properties, microstructure evolution, failure super-plasticity, peening effects and temperature distribution, as well as post weld heat treatment effects [14-20]. As part of the optimization of processing parameters and following a previous investigation [21, 22], an optimal weld obtained during this process requires more knowledge of the microstructural-textural as well as the mechanical properties evolutions. In the current study, a microstructural and textural characterization of 7075-T6 after FSW has been undertaken. The texture evolution was measured using local electron backScatter diffraction (EBSD) and global neutron diffraction (ND) techniques. Special experimental measurement allowed drawing 2D and 3D plots of the microhardness.

Moreover, the evolution of the Young's modulus (E) in different zones through the weld was treated too using two different methods. The first one, destructive, was the nanoindentation technic which use the inverse method of calculations [23]. The second one was the ultrasonic method which has the advantageous to be nondestructive, easy, inexpensive and fast to use in situ. Very few works have used ultrasound techniques to measure E in FSW process except Caroline et al. [24] published data on 2024-T3 aluminum alloy. In the present work, the invest igations concerned only the 7075-T6 alloy. The obtained results were compared to those derived from instrumented indentation tests and discussed.

\section{Experimental procedure}

The material used in this investigation was a 7075 alloy with dimensions of $200 \mathrm{~mm} \times 250 \mathrm{~mm} \times 3 \mathrm{~mm}$. The chemical composition of this alloy is presented in Table 1 . The considered material has been subjected to a T6 heat treatment, which comprises solubilisation, a quench in water and artificial ageing. The used FSW tool is made from a 42CD4 treated steel "a low alloyed" (EN 10027-1). The main elements of FSW tool are the shoulder and pin. The shoulder diameter is $20 \mathrm{~mm}$ associated with a conical threaded pin having 6 and $5 \mathrm{~mm}$ as upper and lower diameters, respectively, and $2.7 \mathrm{~mm}$ length (Fig. 1a). However the pin was made from AISI H11, owing to its very good mechanical resistance at high temperatures and good toughness. The used 42CD4 steel has the following mechanical properties: tensile strength $R_{m}=860 \mathrm{MPa}$, yield strength $R_{p 0.2}=730 \mathrm{MPa}$, density $\rho=7850$ $\mathrm{kg} / \mathrm{m}^{3}$ and elongation $\mathrm{A}=14 \%$. Its chemical composition is listed in Table 2.

The FSW process was carried out with a rotational and a welding speed of $1400 \mathrm{rpm}$ and 60 $\mathrm{mm} / \mathrm{min}$ respectively, a tilt angle of $1^{\circ}$ and applied load of $1375 \mathrm{~N}$. The welding direction 
(WD) was parallel to the rolling direction (RD). The transverse direction (TD) of the welded joint was denoted as cross welding direction (CWD) (Fig. 1).

Table 1: Chemical composition in Wt\% of 7075-T6

\begin{tabular}{ccccccccc}
\hline & $\mathrm{Al}$ & $\mathrm{Si}$ & $\mathrm{Fe}$ & $\mathrm{Cu}$ & $\mathrm{Mn}$ & $\mathrm{Mg}$ & $\mathrm{Zn}$ & $\mathrm{Cr}$ \\
\hline Wt.\% & 89.6 & 0.120 & 0.188 & 1.65 & 0.0202 & 2.47 & 5.66 & 0.208 \\
\hline
\end{tabular}

Table 2: Chemical composition in $\mathrm{Wt} \%$ of $42 \mathrm{CD} 4$

\begin{tabular}{cccccccc}
\hline & $\mathrm{C}$ & $\mathrm{Si}$ & $\mathrm{Mn}$ & $\mathrm{P}$ & $\mathrm{S}$ & $\mathrm{Cr}$ & $\mathrm{Mo}$ \\
\hline Wt.\% & 0.45 & 0.40 & 0.9 & 0.025 & 0.035 & 1.2 & 0.3 \\
\hline
\end{tabular}

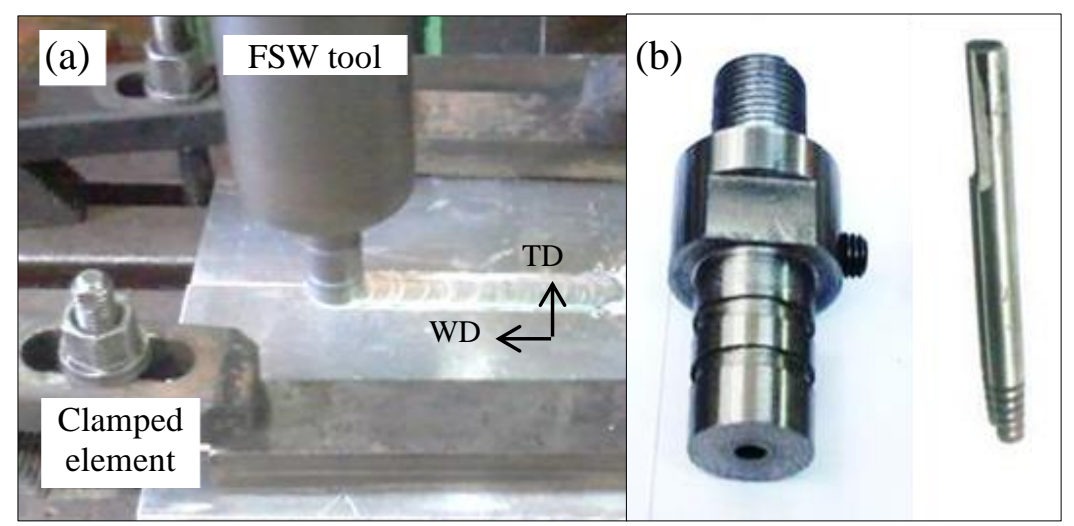

Figure 1: (a) FSW process, (b) Shoulder and pin.

After the welding process, specimens for different analysis were cut from the welding zones: nugget zone (NZ), thermo-mechanically affected zone/heat affected zone (TMAZ / HAZ) and base metal (BM) as indicated in Fig. 2.

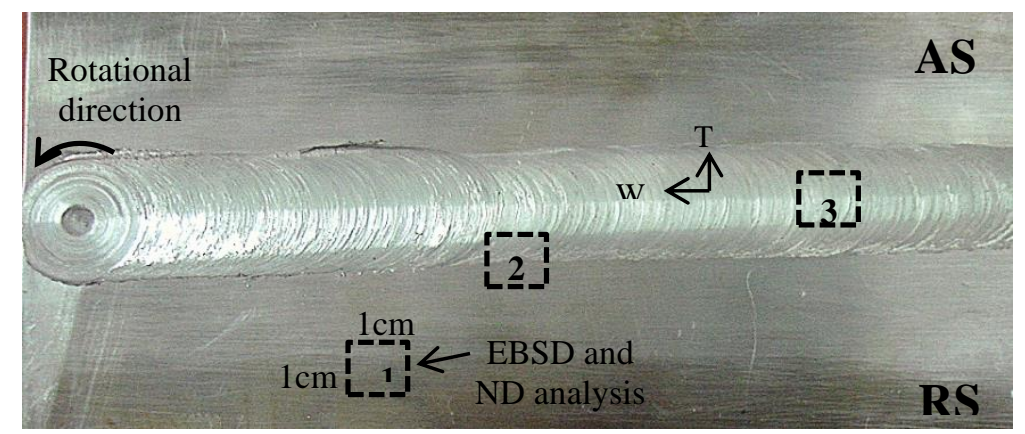

Figure 2: Macrography of the FSW 7075-T6 alloy.

The microstructure and texture were investigated using EBSD in the RD/TD plane at mid-thickness. The samples have been subjected to a mechanical and electro-polishing using the A2 Struers elecrolyte at $25 \mathrm{~V}$. The microstructure was observed using a Scanning Electron Microscope: FEG-SEM SUPRA 55 VP operating at $20 \mathrm{kV}$. The EBSD step size was $50 \mathrm{~nm}$. EBSD data acquisition and analysis were conducted using the TSL orientation 
imaging microscopy with $\mathrm{OIM}^{\mathrm{TM}}$ software. The quantitative texture analysis was carried out by calculating the orientation distribution function (ODF) using $\mathrm{OIM}^{\mathrm{TM}}$ software.

The texture of the samples was determined from neutron diffraction measurements on the 6T1 goniometer in the rolling plane of the sheet at the Léon Brillouin laboratory (CEA, Saclay, France). Sheet packets $\left(1 \mathrm{~cm}^{3}\right)$ were prepared from the FSW processed sheets near the BM, HAZ and the nugget zones (as shown in Fig. 2). A set of three $\{111\},\{200\}$, and $\{220\}$ pole figures using a $5^{\circ} * 5^{\circ}$ grid was used to calculate the orientation distribution function (ODF) using Bunge series-expansion method, with an expansion order of $1_{\max }=22$, using LABOTEX software [www.labosoft.com.pl].

Vickers microhardness was measured on weld cross surface mechanically polished using Wilson micro-hardness tester. The measurements were made on five levels in the transverse direction (TD) through the thickness. A hundred of indentations per level were used to obtain the microhardness values with a load of $100 \mathrm{~g}$ (Hv100) and indentation time of about $10 \mathrm{~s}$.

Local elastic modulus $(E)$ has been determinate firstly by means of nondestructive method. This one is based on ultrasonic time of flight (TOF) measurements to assess the experimental longitudinal $\left(V_{L}\right)$ and shear $\left(V_{s}\right)$ bulk wave velocities. The velocity is given by the following fundamental equation:

$V=\frac{2 e}{T O F}$

Where " $"$ " is the sheet thickness.

The TOF was calculated assuming a homogenous and isotropic sample, using ultrasonic transducers (OLYMPUS) with $5 \mathrm{MHz}$ frequency and diameter of $15 \mathrm{~mm}$, working on pulse echo mode. An ultrasound gel is spread between transducer and specimen. The ultrasonic signals are visualized on a digital GwINSTEK GDS-2102 oscilloscope piloted by a computer, with a band wide of $100 \mathrm{MHz}$ (Fig. 3). The Poisson ratio $v$ and local Young's modulus $E$ (elastic modulus) are calculated using the following relations:

$v=\frac{V_{L}^{2}-2 V_{S}^{2}}{2 V_{L}^{2}-2 V_{S}^{2}}$

$E=2 \rho(1+v) V_{S}^{2}$

where $\rho$ is the sheet density. The measurements have been taken in the different weld zones. Ultrasonic method has the advantageous to be nondestructive, easy, inexpensive and fast but unfortunately, we cannot make measurements only in the TMAZ only because of its narrow width $(\sim 2 \mathrm{~mm})$ comparing to transducer diameter $(15 \mathrm{~mm})$. So, another measurement technique such as the nanoindentation method can be taken on to verify the ultrasonic Young modulus 
measurement results. Although this method is destructive, it allows us to precisely localize the four zones.

Nanoindentation experiments were carried out on an Anton-Paar nano-hardness tester equipped with a Pyramidal Berkovich tip. The loads were between 1 and $500 \mathrm{mN}$, six tests were performed at each zone. The Young modulus was calculated using the model developed by Oliver and Pharr [25].

(1) Impulse generator

(2) Numerical oscilloscope

(3) Ultrasonic signal

(4) Ultrasound gel

(5) Welded sheet

(6) Ultrasonic transducer

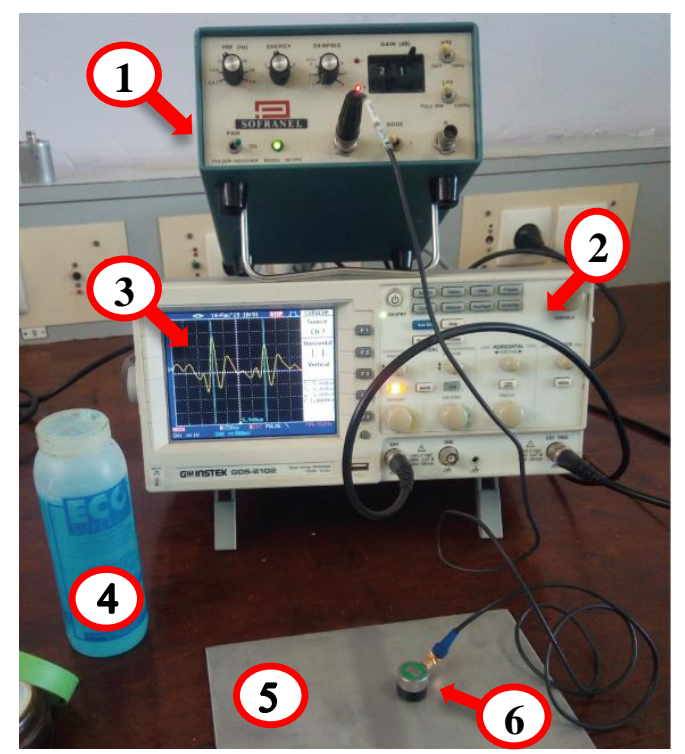

Figure 3: Experimental used set up for the determination of the ultrasonic velocities.

\section{Results and discussion}

\subsection{Macrostructure, microstructure and texture evolution}

The overall macrograph of the 7075-T6 welded sheet exhibits quite good surface appearance with some minor and marginal defects (Fig. 2). The macrostructure consists of four distinct regions including base metal (BM), heat affected zone (HAZ), thermo-mechanically affected zone (TMAZ) and nugget zone (NZ) as shown in Fig. 4. This classification follows the adopted nomenclature on the American Welding Society Standard D17.3M as defined by Threadgill et al. [26, 27].

The orientation imaging micrographs (OIM) in inverse pole figure (IPF) maps in $<001>$ direction of the weld are presented in Fig. 5a-c. These IPF maps were collected in the zones corresponding to BM, HAZ, TMAZ and NZ, respectively. The corresponding SEM images are shown in Fig. 5d-f. 


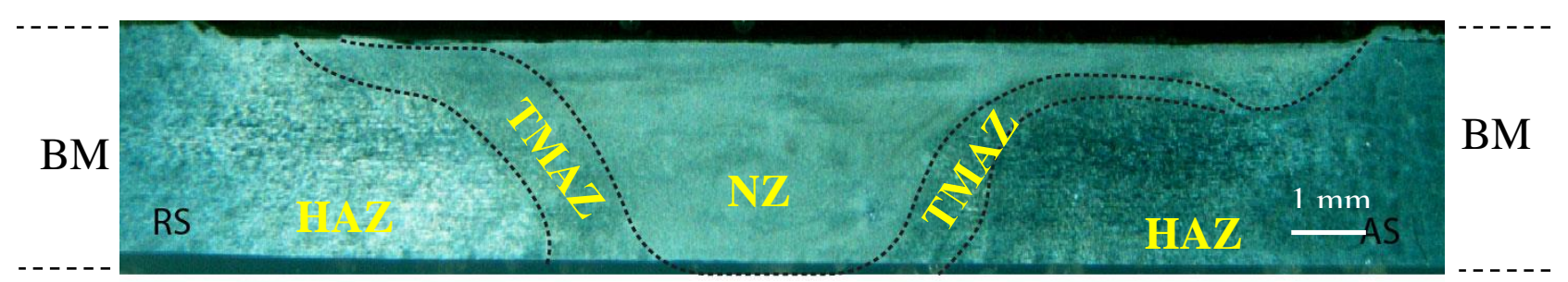

Figure 4: Macrostructure of weld zones in cross section.

The microstructure of BM (Fig. 5a) is characterized by coarse grains morphology, a large number of high angle grain boundaries (HAGBs) and lot of precipitates (indicated by black non index zones and that appear in the grain interior and at the grain boundaries) that should probably be $\mathrm{MgZn}_{2}$ type precipitates [28]. However, Fig. 5b-c reveals that the NZ shows a fine equiaxed grain morphology that exhibits a high fraction of HAGBs. This indicates that a dynamic recrystallization (DRX) process occurred owing to the severe plastic deformation at high temperature during the friction stir welding.

Manifestly, the sharp microstructural (size, morphology, aspect ratio) difference between the $\mathrm{NZ}$ and TMAZ zones is materialized by a net interface as shown in Fig. 5b-e.

In the medium of the sheet thickness, the nugget zone has been located approximately in the weld center line at a width of $4 \mathrm{~mm}$ on both sides of this center line, while the TMAZ which is considered as a transition zone between the HAZ and the NZ, is extended approximately to $1 \mathrm{~mm}$. It worth noting that just near the NZ/TMAZ interface, the grains exhibit strongly sheared and elongated morphology with a shearing direction being fairly opposite to that of tool rotation indicated by curved arrows. This zone belongs to the TMAZ and extends approximately to $200-250 \mu \mathrm{m}$ (Fig. 5b). Fig. 5c and 5f depict the morphology and size of grains in the nugget zone obtained by OIM map and corresponding SEM image (with $35 \mu \mathrm{m}$ in scale).

The considerable variation of grain size from BM to NZ is the evidence that the NZ grains have recrystallized during FSW. Many authors stated that both continuous dynamic recrystallization (CDRX) and discontinuous dynamic recrystallization (DDRX) mechanisms may cause to formation of fine equiaxed grains [29-31]. 

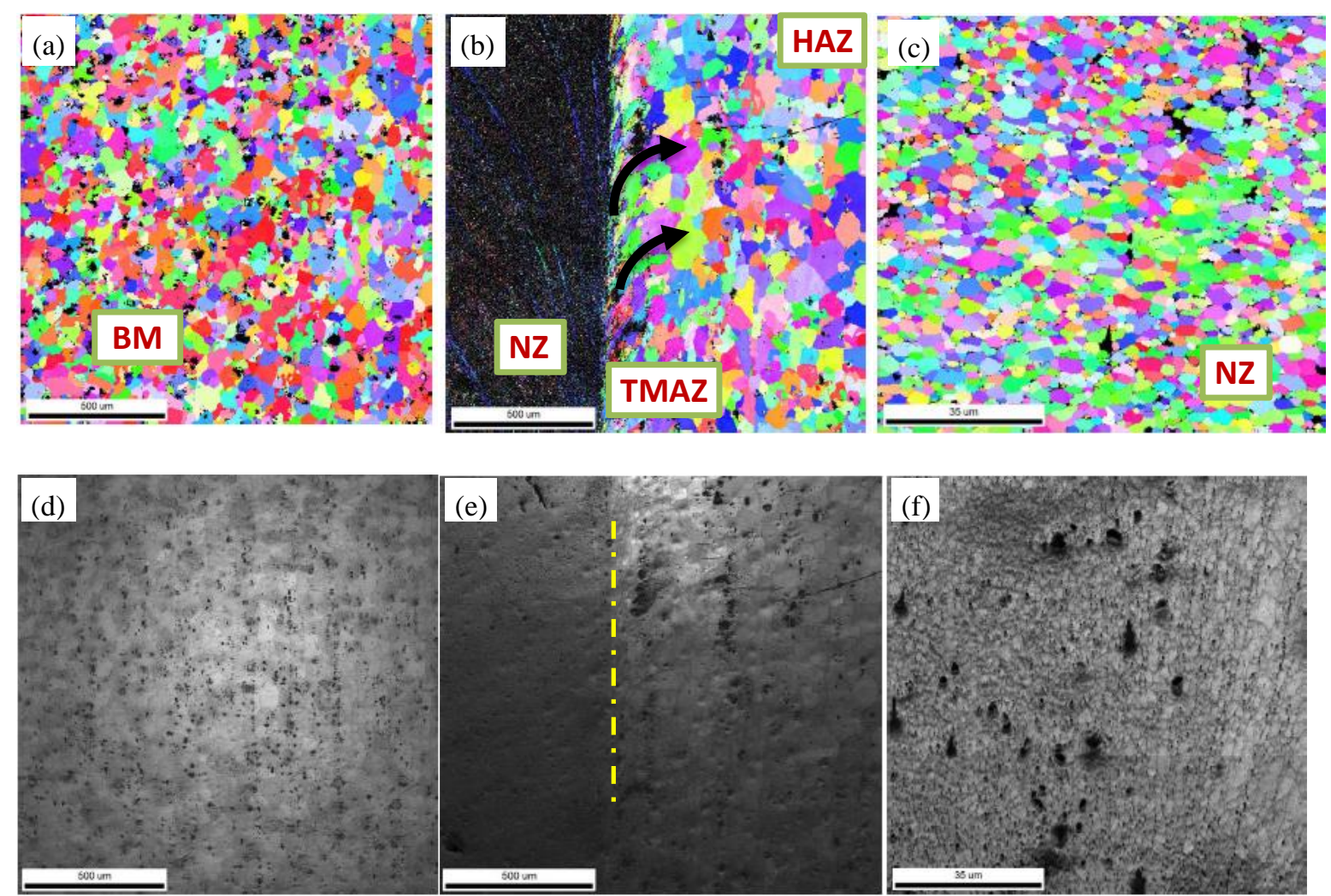

Figure 5: OIM in IPF map and corresponding SEM images obtained from the FSW 7075-T6 alloy in: a-d) BM, b-e) interface between NZ and TMAZ and c-f) NZ, respectively.

The grain size distribution maps in the BM and NZ zones are plotted in Fig. 6 in logarithmic scale. It shows that a substantial grain refinement occurred in the NZ during the FSW process. Indeed, the average grain size in the $\mathrm{MB}$ and $\mathrm{NZ}$ are 52.9 and $1.8 \mu \mathrm{m}$, respectively.

Fig. 7 presents the grain boundary character distribution (GBCD) histograms in the $\mathrm{BM}$ and $\mathrm{NZ}$ zones. The HAGBs and LAGBs are identified by the misorientation angle over $15^{\circ}$ and between 2 and $15^{\circ}$, respectively. 


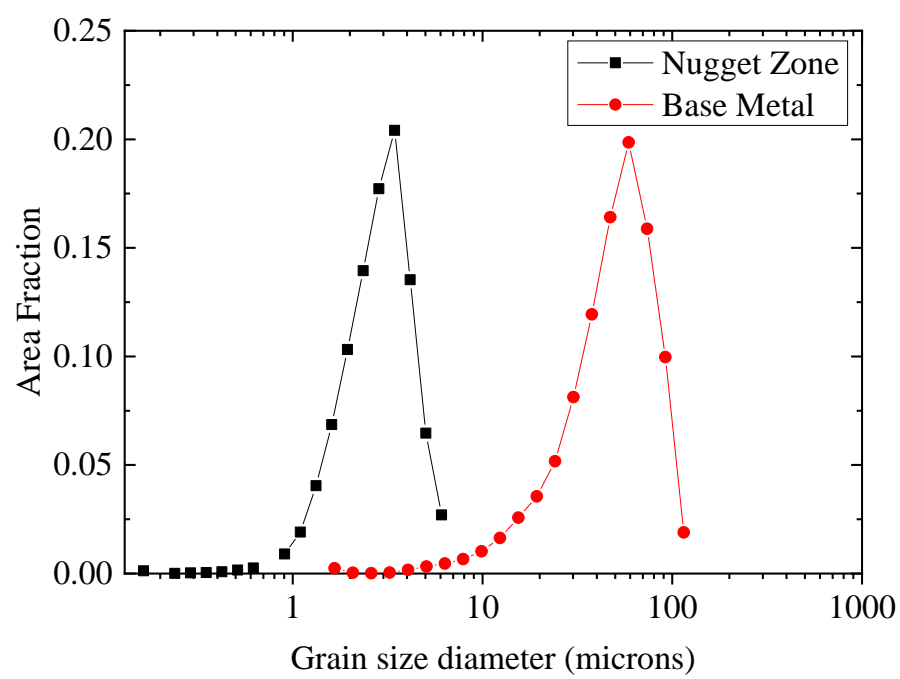

Figure 6: Grain size distribution of the base metal and nugget zones.

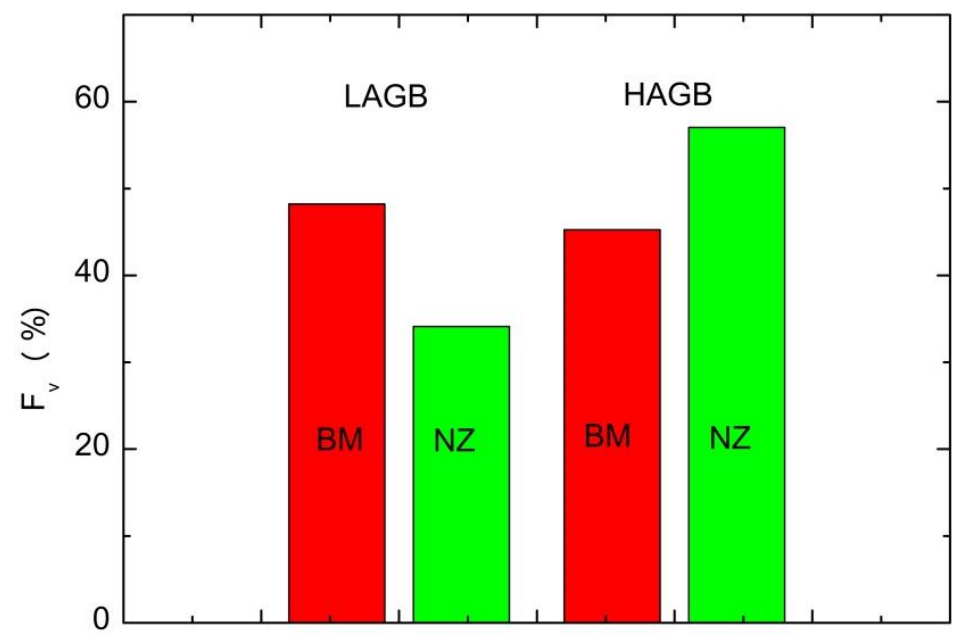

Figure 7: Grain boundary character distribution (GBCD) in the BM and NZ zones.

The texture change during recrystallization and grain growth was analyzed by plotting the orientation distribution function (ODF) sections. Fig. 8 and 9 show the ODF sections at $\varphi_{2}=0$ and $45^{\circ}$ obtained from the EBSD measurements and neutron diffraction (ND) respectively, near the BM and the NZ zones. Since all the pole figures manifested triclinic symmetry rather than orthotropic, the ODF was calculated accordingly.

The intensities of texture components are expressed in multiple of random density (mrd) units. The locations of ideal texture components after recrystallization and simple shear for FCC materials are presented in Fig. 10 and in Table 3. 
Table 3: Ideal positions of main shear and recrystallization texture components in FCC materials taken from [30]

\begin{tabular}{ccccc}
\hline Texture & Miller indices & \multicolumn{3}{c}{ Euler angles $\left(^{\circ}\right)$} \\
\cline { 3 - 5 } components & $(\mathrm{hkl})[\mathrm{uvw}]$ & $\varphi 1$ & $\varphi$ & $\varphi 2$ \\
$\mathrm{~A}_{1}^{*}$ & $(111)[\overline{1} \overline{1} 2]$ & 35.26 & 45 & 0 \\
$\mathrm{~A}_{2}^{*}$ & $(111)[11 \overline{2}]$ & 54.74 & 90 & 45 \\
$\mathrm{~A}$ & $(1 \overline{1} 1)[110]$ & 0 & 35.26 & 45 \\
$\overline{\mathrm{A}}$ & $(\overline{1} 11)[\overline{1} \overline{1} 0]$ & 180 & 35.26 & 45 \\
$\mathrm{~B}$ & $(1 \overline{1} 2)[110]$ & 0 & 35 & 45 \\
$\overline{\mathrm{B}}$ & $(\overline{1} 1 \overline{2})[\overline{1} \overline{1} 0]$ & 60 & 54.74 & 45 \\
$\mathrm{C}$ & $(001)[110]$ & 90 & 45 & 0 \\
& & & & 0 \\
Cube & $(001)[100]$ & $0 / 90$ & 0 & 0 \\
Copper(Cu) & $(112)[111]$ & 90 & 35 & 45 \\
Goss & $(011)[100]$ & 0 & 45 & 0 \\
\hline
\end{tabular}

As obviously seen in Fig. 8, the main texture components of the 7075-T6 base metal are $\{001\}<100>$ Cube and $\{011\}<100>$ Goss. In the NZ, it can be clearly seen that the texture is dominated by simple shear texture components $\mathrm{A}_{1}{ }^{*}, \mathrm{~A}_{2}{ }^{*}, \mathrm{~A}, \overline{\mathrm{A}}, \mathrm{B}$ and $\overline{\mathrm{B}}$. The $\mathrm{B}$ and $\overline{\mathrm{B}}$ components largely dominates (with intensity $\sim 4.2 \mathrm{mrd}$ ) over $\mathrm{C}$ orientation. In general, shear deformation occurs by glide on $\{111\}$ planes in $<110>$ type direction. This results in the formation of two partial fibers called A and B and denoted $\{111\}<\mathrm{uvw}>$ and $\{\mathrm{hkl}\}<110>$, respectively. Along the $\mathrm{A}$ fiber, the most intense are the $\mathrm{A}, \overline{\mathrm{A}}, \mathrm{A}_{1}$ *and $\mathrm{A}_{2}$ * components, while the $\mathrm{B}$ fiber contains the $\mathrm{A}, \overline{\mathrm{A}}, \mathrm{B}, \overline{\mathrm{B}}$ and $\mathrm{C}$ ideal orientations [33].

From Fig. 9, it is obvious that neutron diffraction measurements enabled to evidence the same texture components of the BM with approximately close maximum intensities ( $\sim 5.2 \mathrm{mrd})$. It is worth noting that the Cube component is still visible in the NZ zone but with very weak intensity. The Cube texture component is known to be metastable in the FSW process at ambient temperature [34]. Surprisingly, the texture measured and calculated near the NZ is 
almost different of that obtained through EBSD experiments and consists mainly of weak Cube and Goss recrystallization components with intensities that did not exceed $2.1 \mathrm{mrd}$.

Two main causes should explain why these shear components are not evidenced by neutron diffraction in the present study. The first is inherently associated with the well-known under-estimation of volume fraction $\left(\mathrm{F}_{\mathrm{v}}\right)$ and intensity by neutron diffraction-based technique [35] and hence the minority $\mathrm{A}_{1} *, \mathrm{~A}_{2} *, \mathrm{~A}, \overline{\mathrm{A}}, \mathrm{B}, \overline{\mathrm{B}}$ and $\mathrm{C}$ shear components should be « invisible », i.e. their expected volume fraction would be less than a cut off value $(\sim 2-3 \%)$. However, evident shear texture components are seen in Fig. 9b and correspond to $\mathrm{B}$ and $\overline{\mathrm{B}}$ orientations. Similar extinction of shear components during the measurement of texture via neutron diffraction have been reported by Azzeddine et al. [36] in a Fe-Ni alloy processed by accumulative roll bonding and subsequent ageing.

The second cause arose from the fact the samples for neutron diffraction (stacked sheet packet) must have specific dimensions of $1 \times 1 \times 1 \mathrm{~cm}^{3}$. They were cut, as shown in Fig. 2, in an area which encompasses the BM and the TMAZ/ NZ zones. These latter extend beyond $2 \mathrm{~mm}$ over the limit of the nugget zone. Consequently, the almost and global texture obtained by neutron diffraction should be influenced by that of TMAZ/HAZ zones. HAZ zone is known to exhibit a texture that is often close to BM one [37]. As stated in [38], although the TMAZ undergoes plastic deformation, recrystallization does not occur entirely in this zone due to insufficient deformation strain. Beyond the TMAZ, in the HAZ, there is no plastic deformation, only a thermal cycle experiences in this zone. It has been evidenced that the HAZ retained the same grain structure (morphology) as the base material.

Quite similar results of texture evolution have been reported by Ahmed et al. [39] on AA2017A FSW processed alloy. However, no such evolution of texture was evidenced in AA2024 [40]. These authors claimed that the recrystallization occurred in the FSW joined samples and this phenomenon led to the decrease in the initial orientation that was characterized by the $\alpha$ fiber (that containes Goss and Brass components) and $\tau$-fibrer (that goes from Copper to Goss orientations) while the Copper and Goss orientations remarkably increased.

Texture of the friction stir welded Al-based alloys has been intensively analyzed [40-44]. This texture near the NZ was found as shear deformation process type and follows the torsion texture or simple shear texture of FCC materials [36, 40]. The texture of the NZ exhibited

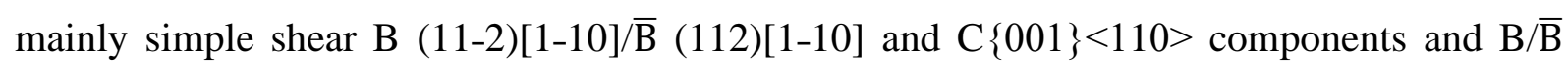
components dominated. Such a texture has also been evidenced in an ultrafine-grained (UFG) 
Al-0.2 Wt.\% Sc sheet, fabricated by accumulative roll bonding and subsequently welded by applying FSW process [45].

The occurrence of recovery during FSW is indubitable owing to the high stacking fault energy of 7075-T6 alloy $\left(\gamma_{\mathrm{SFE}}>170 \mathrm{mJm}^{-2}\right)$. The texture evolution is associated with the deviator stress states. FSW process needs the forward motion of the rotating tool toward the welding direction. This introduces several stresses in the material. The texture in the NZ is mainly related to the stresses at the backside of the tool that are generated by the rotation of the tool shoulder and the cylindrical pin [46].

Since the NZ zone exhibits recrystallized fine grains with shear texture accompagnied by minor Cube component let's enforces the possibility that the weld zone was dynamically recrystallized during plastic flow. It could experience a subsequent statical recrystallization after the rotating pin passes. Many authors stated that the dynamic recrystallization was responsible of the fine recrystallized microstructure [47-50]. However, very few is known about the effective role fo static recrystallization.

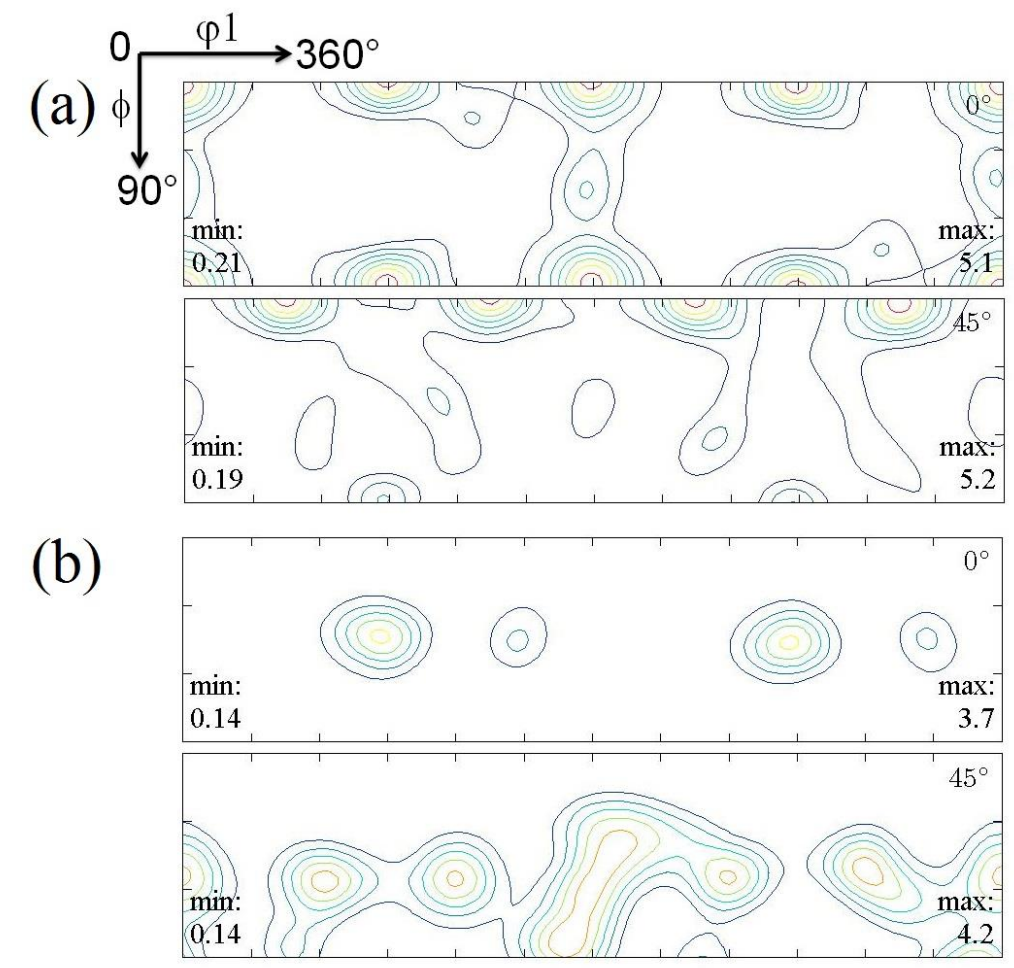

Figure 8: ODF sections at $\varphi_{2}=0^{\circ}$ and $45^{\circ}$ obtained from the EBSD measurements near

(a) BM zone and (b) NZ, respectively. 


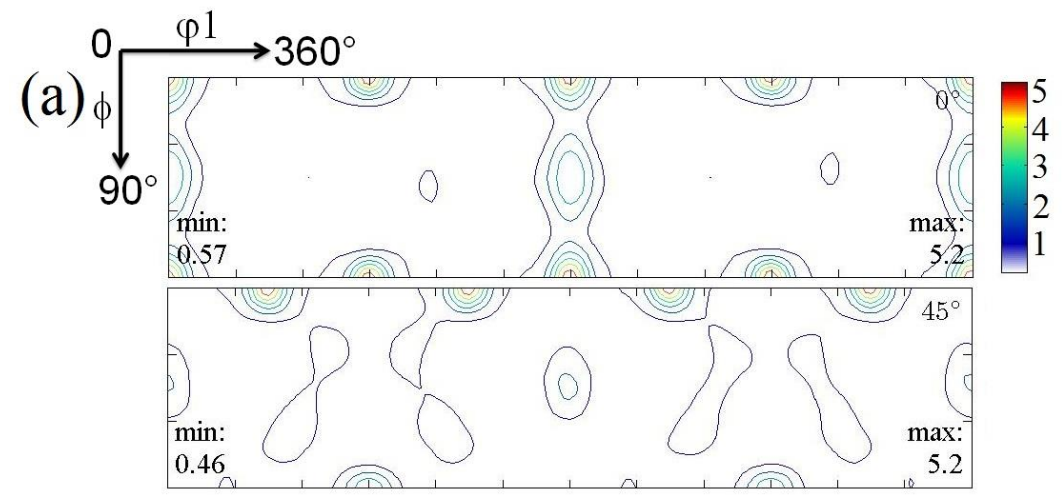

(b)

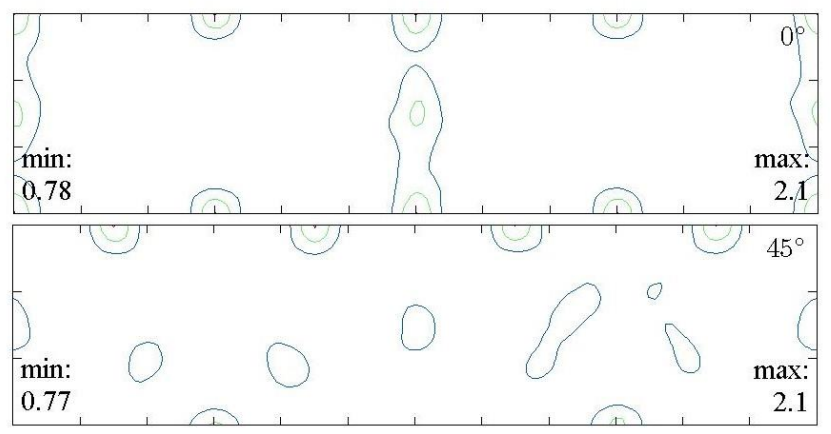

Figure 9: $\mathrm{ODF}$ sections at $\varphi_{2}=0^{\circ}$ and $45^{\circ}$ obtained from the neutron diffraction measurements near (a) BM and (b) NZ, respectively.

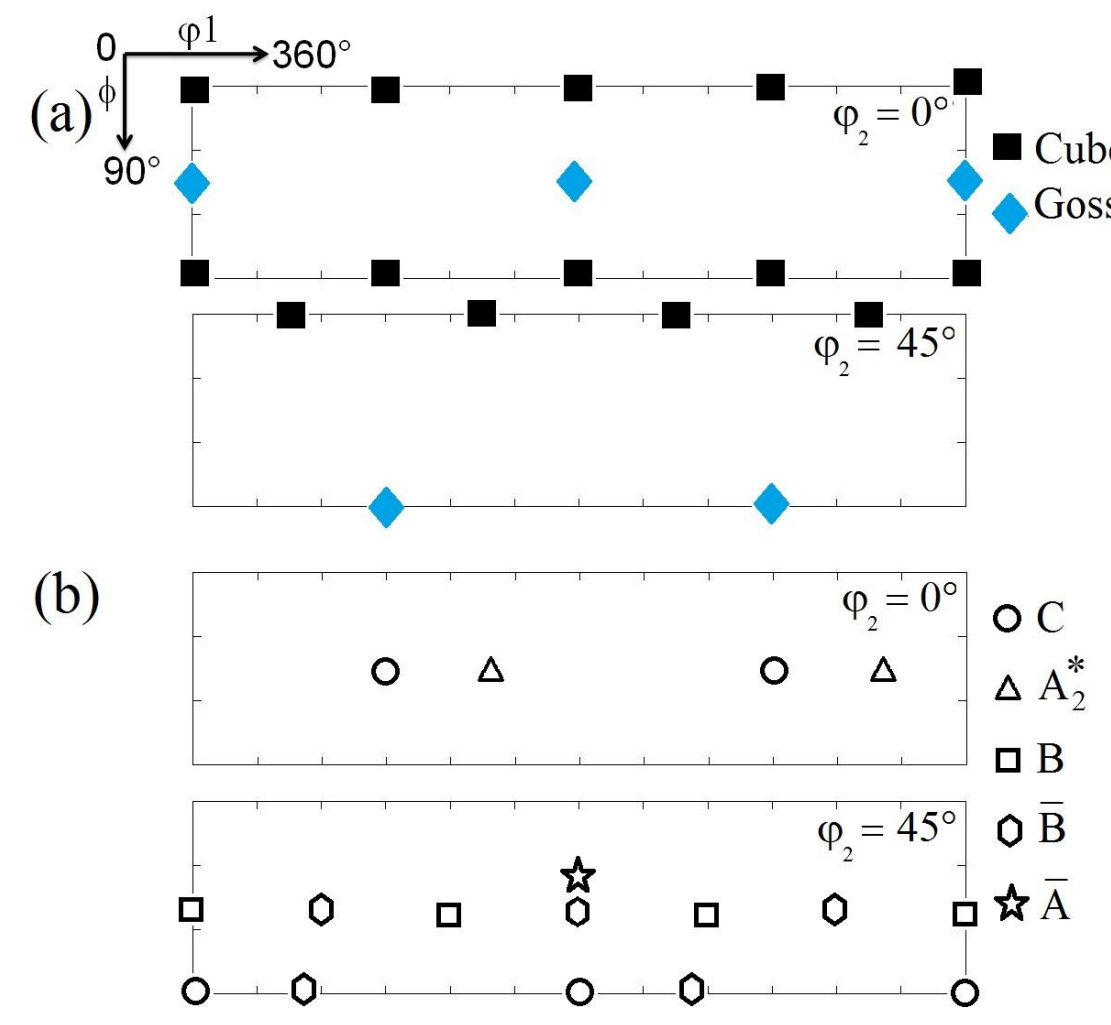

Figure 10: The locations of the ideal (a) recrystallization components in FCC materials components and (b) simple shear texture components. 


\subsection{Microhardness distribution}

Fig. 11a presents a three dimensional view of Vickers microhardness through the welded zones. Two minor extremum are observed describing the typical $\mathrm{W}$ shaped profile. An important change for the microhardness values between the HAZ and TMAZ $(\sim 103 \mathrm{Hv})$ with respect to the $\mathrm{NZ}(\sim 150 \mathrm{Hv})$ and $\mathrm{BM}(183 \mathrm{Hv})$ is noticed. The HAZ has probably undergone an "over aging" because of the high temperature reached during welding that caused a certain growth of the grains and precipitate particles in this zone compared to BM as assumed by Ambriz et al. [23]. The increase of the microhardness in the nugget zone might be due to smaller grain size in this region and the re-precipitation of the hardening phase and the existence of grain boundary precipitate as stated in [38].

To better characterize the microhardness distribution and localize the soft zone highlighted by Vickers microhardness low isovalues, a two dimensional microhardness map was plotted accordingly (Fig. 11b). It can be clearly seen that near blue color corresponds to the TMAZ (purple in Fig. 11a) where the minimum microhardness is reached $(103 \mathrm{Hv})$. The overall evolution of the microhardness seems to be corroborated by Fig. 11.

(a)

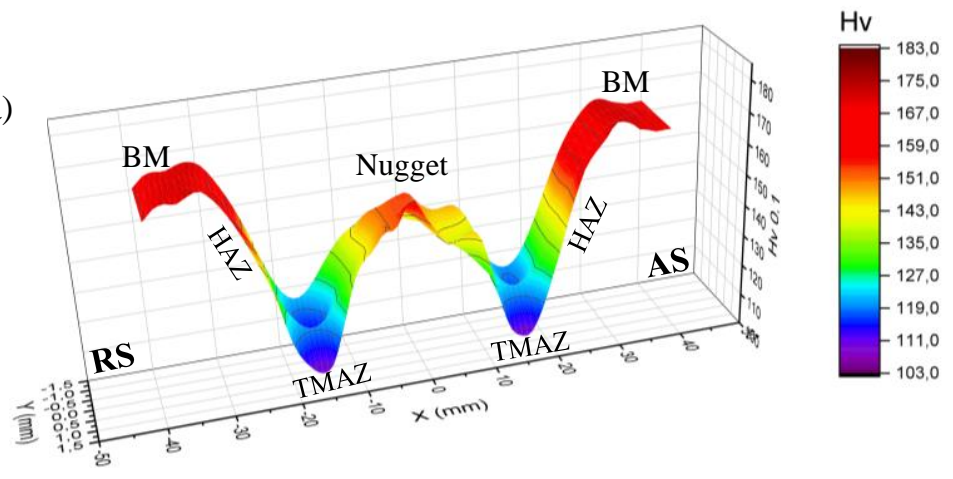

(b)

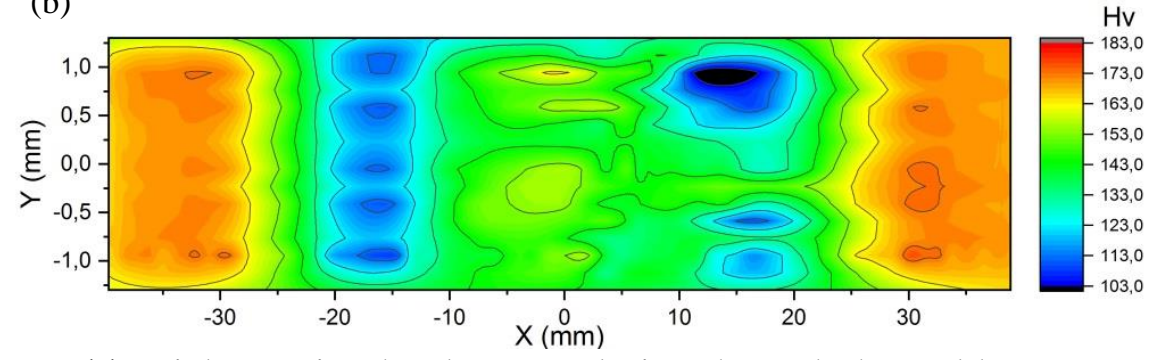

Figure 11: Vickers microhardness evolution through the weld on cross setion ( $x$ and $y$ coordinates): (a) 3D view and (b) 2D isovalue map.

\subsection{Young's modulus measurements}

Fig. 12 shows the utrasonic signals for shear and longitudinal bulk waves in BM, HAZ and NZ. The width of the TMAZ is very small compared to transducers diameter so the signals obtained in the HAZ and TMAZ are superimposed. For this reason, only one signal has been 
represented. From Fig. 12, no important TOF differences was observed in the HAZ (or TMAZ) and NZ with respect to BM. The calculated Poisson ratio and elastic modulus are presented in Table 4.

Table 4: Experimental values of the mechanical properties of 7075-T6 alloy.

\begin{tabular}{|c|c|c|c|}
\hline & BM & HAZ & NZ \\
\hline $\boldsymbol{v}$ & $0.34 \pm 0.01$ & $0.34 \pm 0.01$ & $0.34 \pm 0.01$ \\
\hline$E(\mathrm{GPa})$ & $67.5 \pm 0.8$ & $66.2 \pm 0.8$ & $70.3 \pm 0.8$ \\
\hline
\end{tabular}

The Poisson ratio is an intrinsic property of the material that often changes very slightly during thermomechanical processing. The experimental values obtained are the same in the different zones and very close to the theoretical one (0.33) for pure $\mathrm{Al}$ and its alloys [51].

Regarding to the Young's modulus, the results show a small difference between the values calculated in each zone. In the NZ, the Young's modulus is equal to $70.3 \mathrm{GPa}$, it experiences an increase of $2.8 \mathrm{GPa}(\sim 4.2 \%)$ relatively to the $\mathrm{BM}$ one. This variation can be expected from the microstructural observation where the fine grains are obtained in the NZ. The same conclusions were drawn by Carlone et al. [24] who noted an increase of $4.6 \%$ in NZ with respect to the base metal modulus. However, a slight decrease of $1.3 \mathrm{GPa}(\sim 1.9 \%)$ is measured in the HAZ/TMAZ compared to BM. This softening may be associated with a decrease of the microhardeness in this zone.

In order to validate the previously results by local investigation, nanoindentation measurements were also carried out. Fig. 13 shows the mean Young's modulus resulting from six indentations in each zone as a function of the different zones. The Young modulus value in the BM zone is quite close to that in NZ however, it slightly decreases in the softened HAZ and TMAZ zones.

Table 5 summarises the elastic modulus obtained by ultrasonic (US) and nanoindentation techniques. The difference (in \%) between the values obtained via both techniques is also given.

Table 5: Comparison of ultrasonic elastic modulus measurement by the nanoidentation method.

\begin{tabular}{lcccc}
\hline $\mathrm{E}(\mathrm{GPa})$ & $\mathrm{BM}$ & $\mathrm{HAZ}$ & $\mathrm{TMAZ}$ & $\mathrm{NZ}$ \\
\hline EUS $_{\text {U }}$ & 69 & 66.2 & 66.2 & 70.3 \\
Enano $_{\text {Diff }(\%)}$ & 72.0 & 65.7 & 65.1 & 70.8 \\
& 4.1 & 0.76 & 1.68 & 0.70 \\
\hline
\end{tabular}

The Young modulus in both methods decreases in the HAZ and TMAZ with respect to the BM. It increases in the NZ. Furthermore, it can be observed that the difference between the 
two methods results is negligeable which indubitably indicates an acceptable agreement between the achieved techniques.
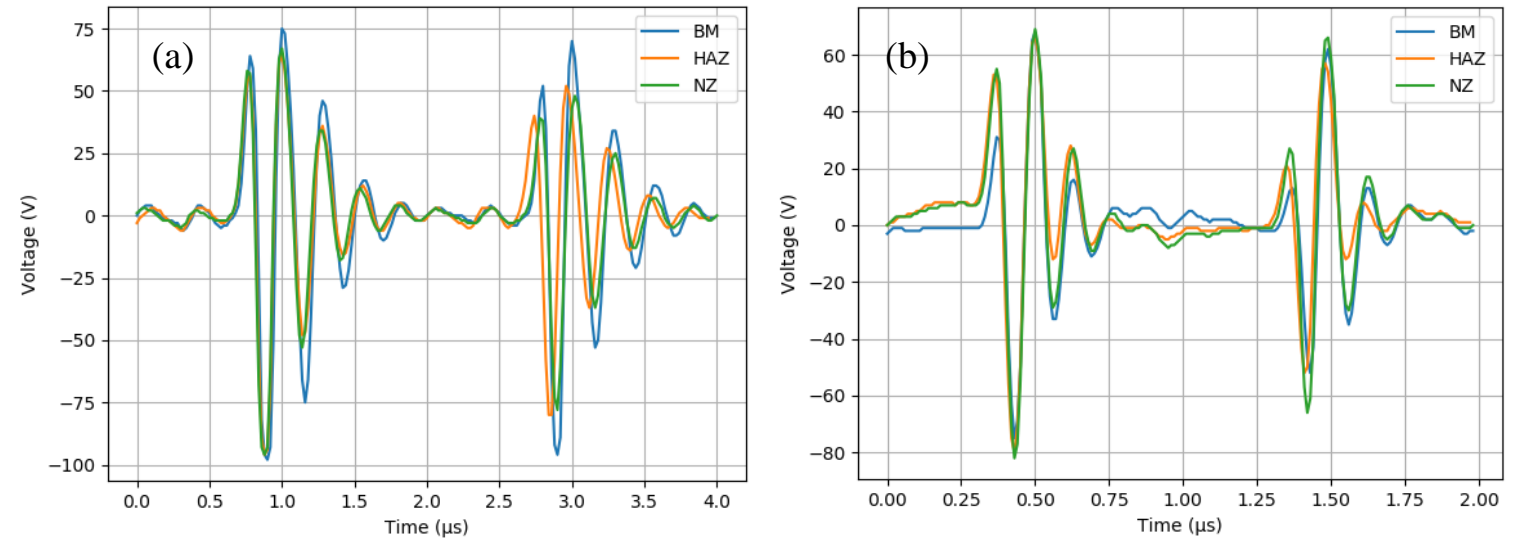

Figure 12: Utrasonic signals tor: (a) shear and (b) longitudinal bulk waves in the BM, HAZ and NZ.

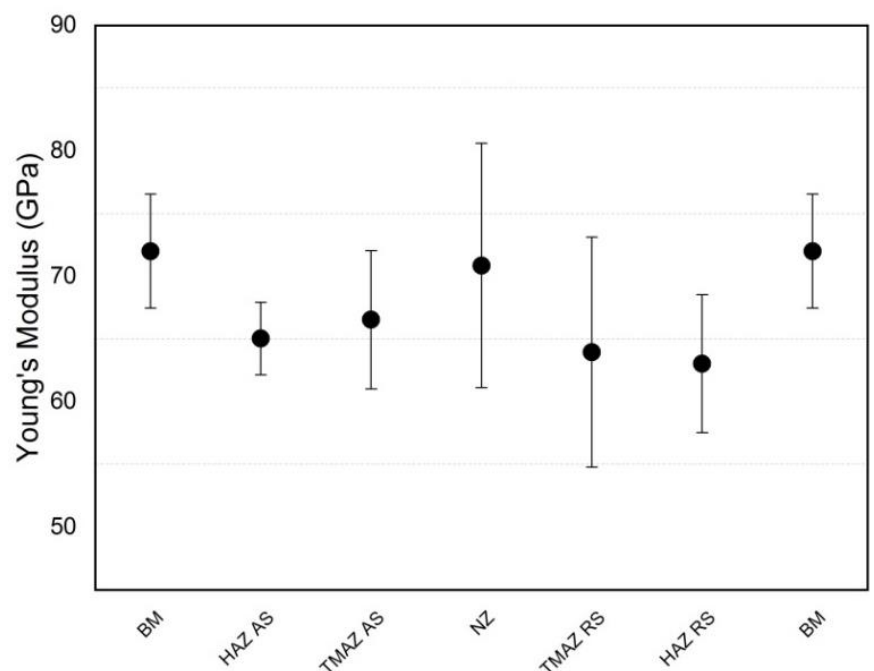

Figure 13: Evolution of the mean elastic modulus obtained in the four zones over AS and RS.

\section{Conclusions}

The microstructure, crystallographic texture and mechanical properties of FSWed aluminium alloys 7075-T6 have been investigated and the most important results are:

- The NZ contained fine equiaxed and fully recrystallized grains while BM consisted of coarse grains. The average grain size in the MB and NZ were 52.9 and $1.82 \mu \mathrm{m}$.

- The NZ showed a high fraction ( $57 \%$ ) of HAGBs. This indicated that a dynamic recrystallization (DRX) process occurred owing to the severe plastic deformation at high temperature during the friction stir welding.

- The texture of the BM mainly consisted of recrystallization Cube and Goss components. In the stir zone, the dominant texture components were $\mathrm{B}$ and $\bar{B}$ component among faint other shear orientations. 
- EBSD and neutron diffraction techniques resulted in identical texture in the BM zone. While totally, different textures were measured near the stirred zone.

- The drop of microhardness in the HAZ might probably be caused by an over aging and a re-precipitation of the hardening phase and the existence of grain boundary precipitates.

- An evident correlation has been found between the ultrasonic measurements of Young modulus and nanoindentation method.

\section{References:}

[1] Hidalgo-Manrique, P., Cepeda-Jimenez, C.M., Ruano, O.A., and Carreno, F., Effect of warm accumulative roll bonding on the evolution of microstructure, texture and creep properties in the 7075 aluminium alloy, Mat. Sci. Eng. A, 2012, vol. 556, pp. 287-294.

[2] Mao, Y., Ke, L., Liu, F., Liu, Q., Huang, C., and Xing, L., Effect of tool pin eccentricity on microstructure and mechanical properties in friction stir welded 7075 aluminum alloy thick plate, Mater. Des, 2014, vol. 62, pp. 334-343.

[3] Fonda, R.W., and Bingert, J.F., Texture variations in an aluminum friction stir weld, Scr. Mater, 2007, vol. 57, pp. 1052-1055. DOI: https://doi.org/10.1016/j.scriptamat.2007.06.068.

[4] Diwahar, S., Anbarasu, K., Deepanchakravarthy, P., and Raveen, R., A review on friction stir welding of similar and dissimilar aluminium alloys, Int. Research J. of Engineering and Technol, 2017, Vol. 04, no. 10.

[5] Huang, Y., Xie, Y., Meng X., and Li, J., Atypical grain coarsening of friction stir welded AA6082-T6: Characterization and modeling, Mater. Sci. Eng. A, 2019, 740-741, pp. 211-217.

[6] $X u, X ., L u, Y$., Zheng, F., and Chen, B., Microstructural Investigation of Friction-StirWelded 7005 Aluminum Alloy, J. Mater. Eng. Perform, 2015, vol. 24, pp. 4297-306.

[7] Fonda, R., Knipling, K., and Bingert, J., Microstructural evolution ahead of the tool in aluminum friction stir welds, Scr. Mater, 2007, vol. 58, pp. 343-348.

[8] Gachi, S., Boubenider, F., and Belahcene, F., Residual stress, microstructure and microhardness measurements in AA7075-T6 FSW welded sheets, J. of Nondestr. Testing and Eval, 2011, vol. 26, no. 1, pp. 01-11. DOI : https://doi.org/10.1080/10589751003658040.

[9] Wang, B., Lei, B., Zhu, J., Feng, Q., Wang, L., and Wu, D., EBSD study on microstructure and texture of friction stir welded AA5052-O and AA6061-T6 dissimilar joint, Mater. Des, 2015, vol. 87, pp. 593-9. DOI : https://doi.org/10.1016/j.matdes.2015.08.060.

[10] Imam, M., Racherla, V., Biswas, K., Fujii, H., Chintapenta, V., and Sun Y., Microstructure-property relation and evolution in friction stir welding of naturally aged 6063 aluminium alloy, Int. J. Adv. Manuf. Technol, 2017, vol. 91, pp. 1753-69. 
[11] Peel, M., Steuwer, A,. Preuss, M,. Withers, PJ., Microstructure, mechanical properties and residual stresses as a function of welding speed in aluminium AA5083 friction stir welds, Acta. Mater, 2003, vol. 51, pp. 4791-801. DOI: https://doi.org/10.1016/S1359-454(03)00319-7.

[12] Prangnell, $P B$,. and Heason, CP., Grain structure formation during friction stir welding observed by the stop action technique, Acta. Mater, 2005, vol. 53, pp. 3179-92.

[13] Cho, J.H., Kim, W.J., and Lee, C.G., Texture and microstructure evolution and mechanical properties during friction stir welding of extruded aluminum billets. Mat Sci. Eng. A, 2014, vol. 597, pp. 314-323. http://dx.doi.org/10.1016/j.msea.2013.12.087.

[14] Zhang, J., Upadhyay, P., Hovanski, Y., and Field, D.P., High-Speed Friction-StirWelding of AA7075-T6 sheet: Microstructure, Mechanical properties, Micro-texture and thermal history, Metall. Mater. Trans. A, 2017. DOI: 10.1007/s11661-017-4411-4.

[15] Dieguez, T., Burgueño, A., Svoboda, H., Superplasticity of a Friction Stir Processed 7075-T651 aluminum alloy, Procedia Mater. Sci, 2012, vol. 1, pp. 110-117.

[16] Rajakumar, S., Muralidharan, C., and Balasubramanian. V., Influence of friction stir welding process and tool parameters on strength properties of AA7075-T6 aluminium alloy joints. Mater. Des, 2011, vol. 32, pp. 535-549.

[17] Rezaei, H., Mirbeik, MH., and Bisadi, H., Effect of rotational speeds on microstructure and mechanical properties of friction stir-welded 7075-T6 aluminium alloy, J. Mech. Eng. Sci, 2011, vol. 225, pp. 1761-73. DOI: https://doi.org/10.1177/0954406211404633.

[18] Jata, KV., Sankaran, KK., Ruschau, JJ., FSW on microstructure and fatigue of aluminum alloy 7050-T7451, Metall. Mater. Trans. A, 2000, vol. 31, pp. 2181-92.

[19] Denquin, A., Allehaux, D., Campagnac, MH., Lapasset, G., Microstructural and mechanical evolutions within friction stir welds of precipitation hardened aluminium alloys, Mater. Sci. Forum, 2003, vol. 426-432, pp. 2921-6.

[20] Reynolds, AP., Lockwood, WD., and Seidel, TU., Processing-Property Correlation in Friction Stir Welds, Mater. Sci. Forum, 2000, vol. 331-337, pp. 1719-24. DOI: https://doi.org/10.4028/www.scientific.net/MSF.331-337.1719.

[21] Boukraa, M., Lebaal, N., Mataoui A., Friction stir welding process improvement through coupling an optimization procedure and three-dimensional transient heat transfer numerical analysis. J. of Manufac. Process, 2018, vol. 34, pp. 566-578.

[22] Aissani, M., Gachi, S., Boubenider, F., and Benkedda., Design and Optimization of Friction Stir Welding Tool: Materials and Manufacturing Processes, J. of Mater. and Manufac. Process, 2010, vol. 25, no. 11, pp. 1199-1205. 
[23] Ambriz, R.R., Chicot, D., Benseddiq, N., Mesmacque, G., de la Torre S.D., Local mechanical properties of the 6061-T6 aluminium weld using micro-traction and instrumented indentation. Eur. J. Mech. A/Solids, 2011, vol. 30, pp. 307-315.

[24] Carlone, P., and Palazzo, G. S., Longitudinal Residual Stress Analysis in AA2024-T3

Friction Stir Welding, Open Mech Eng J, 2013, vol. 7, no. 19, pp. 18-26.

[25] Oliver, W.C., and Pharr, G.M., An improved technique for determining hardness and elastic modulus using load and displacement sensing indentation experiments, J. Mater. Res, 1992, vol. 7, no. 6, pp. 1564-1583. DOI: https://doi.org/10.1557/JMR.1992.1564.

[26] Specification for friction stir welding of aluminum alloys for aerospace applications', Standard D17.3:200X, American Welding Society, Miami, FL, USA, 2006.

[27] Threadgill, P.L., Leonard, A.J,. Shercliff, H.R P. Withers, J., Friction stir welding of aluminium alloys, Int. Mater. Rev, 2009, vol. 54, no. 2, pp. 49-93.

[28] Mishra, R.S., and Mab, Z.Y., Friction Stir Welding and Processing, Mater. Sci. Eng., R. 2005, vol. 50, pp. 1-78. DOI: https://doi.org/10.1016/j.mser.2005.07.001.

[29] Mironov, S., Inagaki, K., Sato, Y.S., Kokawa, H., Microstructural evolution of pure copper during friction-stir welding, Philos. Mag. 2015, vol. 95, pp. 367-381.

[30] Jeon, J., Mironov, S., Sato, Y., Kokawa, H., Park, S., and Hirano, S., Grain Structure Development During Friction Stir Welding of Single-Crystal Austenitic Stainless Steel, Metall. Mater. Trans. A, 2013, vol. 44, pp. 3157-3166. DOI: https://doi.org/10.1007/s11661-013-1692-0.

[31] Saeid, T., Abdollah-zadeh, A., Shibayanagi, T., Ikeuchi, K., and Assadi, H., On the formation of grain structure during friction stir welding of duplex stainless steel, Mater. Sci. Eng. A, 2010, vol. 527, pp. 6484-6488. DOI: https://doi.org/10.1016/j.msea.2010.07.011.

[32] Heidarzadeh, A., Saeid, T., and Klemm, V., Microstructure, texture, and mechanical properties of friction stir welded commercial brass alloy, Mater. Charact, 2016, vol. 119, pp. 84-91. [33] Valiev, R.Z. Zhilyaev, A. P. and Langdon, T.G., Fundam. Appl,Germany, 2014.

[34] Chen, S., Jiang, X., Texture evolution and deformation mechanism in friction stir welding of 2219Al, Mater. Sci. Eng. A, 2014, vol. 612, pp. 267-277.

[35] Bolmaro, R.E., and Brokmeier, H.G., X-ray and neutron diffraction measurement of texture of two phase-materials, 12th Int. Conf on Textures of Mat, Canada. 1999, pp. 211-216. [36] Azzeddine, H., Tirsatine, K., Baudin, T., Helbert, A., Mathon, M., Brisset, F., and Bradai, $D$., Neutron diffraction versus EBSD analysis of the texture in Fe-36\%Ni alloy after accumulative roll bonding, Indian J. of Eng. Mat. Sci, 2017, vol. 24, pp. 35-44. 
[37] Cho, J.H., Won, J.K., Chang, G.L., Texture and microstructure evolution and mechanical properties during friction stir welding of extruded aluminum billets, Mater. Sci. Eng. A, 2014, vol. 597, pp. 314-323. DOI: https://doi.org/10.1016/j.msea.2013.12.087.

[38] Gan, W., Zhou, Z., Zhang, H., and Peng, T., Evolution of microstructure and hardness of aluminum after friction stir processing, Trans. Nonferrous Met. Soc. China, 2014, vol. 24, pp. 975-981. DOI: https://doi.org/10.1016/S1003-6326(14)63151-4.

[39] Ahmed, M.M.Z., Wynne, B.P., Rainforth, W.M., and Threadgill, P.L., Microstructure, crystallographic texture and mechanical properties of friction stir welded AA2017A, Mater. Charact, 2012, vol. 64, pp. 107- 117. DOI: https://doi.org/10.1016/j.matchar.2011.12.005 [40] Alvand, M., Naser, M., borhani, E., and Abdollah-Pour, H., Iran. J. Mater. Sci. Eng, 2018, vol. 15 , no. 1 , pp. 53-63.

[41] Prangnell, P.B., and Heason, C.P., Grain structure formation during friction stir welding observed by the 'stop action technique', Acta. Mater, 2005. Vol. 53, pp. 3179-3192.

[42] Jin, H., Saimoto, S., Ball, M., and Threadgill, P.L., Characterisation of microstructure and texture in friction stir welded joints of 5754 and 5182 aluminium alloy sheets, Mater. Sci. Technol. 2001, vol. 17, pp. 1605-1614. DOI: https://doi.org/10.1179/026708301101509674.

[43] Sato, Y.S., Kokawa, H., Ikeda, K., Enomoto, M., Hashimoto, T., and Jogan, S., Microtexture in the Friction-Stir Weld of an Aluminum Alloy, Metall. Mater. Trans. A, 2001, vol. 32, no. 4, pp. 941-948. DOI: https://doi.org/10.1007/s11661-001-0351-z.

[44] Su, J.Q., Nelson, T.W., Mishra, R., and Mahoney, M., Microstructural investigation of friction stir welded 7050-T651 aluminium, Acta. Mater, 2003, vol. 51, pp. 713-729.

[45] Yousefieh, M., Tamizifar, M., Boutorab, S.M.A., and Borhani, E., J Mater Sci, 2017.

[46] Sato, Y.S., kokawa, H., Ikeda, k., Enomoto, M., Jogan, S., and Hashimoto, T., Microtexture in the friction-stir weld of an aluminum alloy, Metall. Mater. Trans.A, 2001, vol. 32a, pp. 941-948. DOI: https://doi.org/10.1007/s11661-001-0351-z

[47] Murr, L.E., Liu, G., and McClure, J.C., A TEM study of precipitation and related microstructures in friction-stir-welded 6061 aluminium, J. Mater. Sci, 1998, vol. 33, pp. 1243-51.

[48] Murr, L.E., Liu, G, and McClure, J.C., Dynamic recrystallization in friction-stir welding of aluminium alloy 1100, J. Mater. Sci. Lett, 1997, vol. 16, pp. 1801-03.

[49] Flores, OV., Kennedy, C., Murr, LE., Brown, D., Pappu, S., Nowak, BM., and McClure, JC., Microstructural issues in a friction-stir-welded aluminum alloy, Scripta Mater, 1998, vol. 38, pp. 703-08. [50] Li, Y., Murr, L.E., and McClure, J.C., Dynamic recrystallization during FSW, Scripta Mater, 1999, vol. 40, pp. 1041-46. DOI: https://doi.org/10.1016/S1359-6462(97)00551-4. [51] http://www.euralliage.com/7075.htm\#pro. 